\title{
Integrated Control of Grape Black Rot: Influence of Host Phenology, Inoculum Availability, Sanitation, and Spray Timing
}

\author{
Lisa Emele Hoffman, Wayne F. Wilcox, David M. Gadoury, Robert C. Seem, and Duane G. Riegel
}

Department of Plant Pathology, Cornell University, New York State Agricultural Experiment Station, Geneva 14456.

Current address of L. E. Hoffman: DuPont Crop Protection Products, E. I. DuPont de Nemours and Co., Stine-Haskell Research Center, Newark, DE 19714.

Accepted for publication 15 January 2004.

\begin{abstract}
Hoffman, L. E., Wilcox, W. F., Gadoury, D. M., Seem, R. C., and Riegel, D. G. 2004. Integrated control of grape black rot: Influence of host phenology, inoculum availability, sanitation, and spray timing. Phytopathology 94:641-650.

The epidemiology and control of black rot (Guignardia bidwellii) was studied from 1995 to 1999 in vineyards in Dresden and Naples, NY, where disease pressure was moderate and extreme, respectively. The efficacy of serial applications of myclobutanil, provided at 2-week intervals and varied with respect to their number and time of initiation, was examined within the context of host phenology, inoculum availability, and sanitation. At Dresden, sprays applied over 4 weeks through the immediate prebloom stage provided only 13 to $91 \%$ control of diseased clusters,

despite the release of $95 \%$ of the season's ascosporic inoculum during the period of fungicidal protection. However, applications immediately prior to bloom plus 2 and 4 weeks later, which afforded protection while fruit are highly susceptible to infection, provided virtually complete control. At Naples, where mummified berries were retained in the canopy after mechanical pruning, this same regime provided only approximately $80 \%$ disease control, but applying a fourth spray 2 weeks prebloom generally improved control. Hand-pruning mummies to the ground in selected plots significantly $(P \leq 0.05)$ improved control in some spray regimes. Although this sanitation practice did not affect inoculum dynamics through bloom, very few spores were recovered thereafter from mummies collected from the ground, whereas abundant ascospores and conidia were recovered from mummies in the trellis for an additional 6 to 8 weeks.
\end{abstract}

Black rot, caused by the fungus Guignardia bidwellii (Ellis) Viala \& Ravaz (anamorph Phyllosticta ampelicida (Englem.) van der $\mathrm{Aa}$ ), is a destructive disease of grapes in many regions with humid growing seasons $(28,31)$. Although young leaves, shoots, and tendrils are susceptible to infection, this seldom results in appreciable damage to vine health. In contrast, infection of the clusters can drastically reduce yield and quality $(4,7-9,28,30,31)$. In addition to controlling such current-season losses, disease management programs also seek to restrict the build-up of primary inoculum for the following year.

G. bidwellii produces both ascospores and conidia in infected fruit that have mummified and overwintered in the vineyard. Ascospores are considered the principal form of primary inoculum $(7,28)$. They begin to mature shortly after budbreak and have been observed inside pseudothecia as late as October in New York (29), although trapping studies have indicated that ascospore release ends in early July ( $\approx 3$ to 4 weeks postbloom) in Switzerland (19) and in September (preharvest) in Michigan (7). In laboratory discharge tests using mummies from New York vineyards, approximately 90 to $100 \%$ of the available ascospores were released by bloom to 1 month postbloom $(1,10)$, although ascospore release occurred even later if mummies were collected from the trellis rather than the ground (1). Conidia, which typically function as secondary inoculum $(8,28)$, also can serve as primary inoculum when released from overwintered mummies $(1,2,26)$ and cane lesions $(3,27,29,31)$. Although the inoculum dynamics and ontogeny of $G$. bidwellii have been examined in some detail $(17,18,23,25,29-31)$, as have the environmental requirements for

Corresponding author: L. E. Hoffman

E-mail address: lisa-emele.hoffman@usa.dupont.com

Publication no. P-2004-0421-01R

(c) 2004 The American Phytopathological Society spore germination $(21,33)$ and host infection $(20,29,31,32-34)$, few studies have examined the interaction of these and other relevant factors (e.g., host phenology and, specific vineyard management practices) with respect to their influence on disease development and control. For instance, mechanical hedging is a nonselective, dormant pruning practice that can retain overwintering inoculum of G. bidwellii and other pathogens within the trellis, which might otherwise be removed selectively during hand pruning (13,27 ). Although this technique reduces labor inputs, it potentially could exacerbate black rot by retaining overwintered cane lesions (3) and mummies $(1,2)$.

Traditionally, control recommendations have emphasized applications of protectant fungicides beginning when shoots are approximately $10 \mathrm{~cm}$ long and continuing until berries reach $5 \%$ sugar (28), or from approximately mid-May through mid-August in the Finger Lakes region of New York. With the advent of the sterol demethylation inhibitor (DMI) fungicides, a reduced-spray program based on curative applications of these materials following a putative infection period (33) was developed and tested successfully (5). This program did not, however, account for variability in inoculum availability or potential age-related changes in host susceptibility as the season progressed. Subsequently, the approach was modified (10) to further restrict such sprays to the presumed period of ascosporic inoculum release. Nevertheless, technical constraints on rapidly applying postinfection sprays have limited the commercial acceptance of such programs. A simpler, alternative approach might be to focus a limited number of fungicide applications to provide protection throughout a period critical for disease development (i.e., when fruit are highly susceptible to infection). However, this critical period was not well defined, nor had the concept been tested prior to the start of the present study. Thus, the objectives of this study were to (i) examine the utility of a reduced-spray program based upon epidemiology, specifically the attendant changes in disease suscepti- 
bility as berries age and associated changes in seasonal inoculum dynamics; and (ii) integrate this concept with that of disease management via sanitation. Portions of this work have been published previously $(5,6,14)$. A detailed companion study concerning the period of berry susceptibility to infection by G. bidwellii also was published (15).

\section{MATERIALS AND METHODS}

Vineyards. Experiments were conducted primarily in two commercial vineyards located in the Finger Lakes region of New York, with treatment plots located in a section of each vineyard where black rot had developed regularly. A hand-pruned vineyard in Dresden, NY, consisting of the Vitis interspecific hybrid 'Aurore', was used from 1995 to 1999. Low to moderate levels of disease developed in this vineyard each year. The second vineyard, consisting of Vitis $\times$ labruscana 'Delaware', in Naples, NY, was added in 1998 and 1999. Repeated mechanical hedge-pruning at this site created vines with large, very dense canopies. The nonselective nature of this pruning technique, and a consistent history of severe black rot development, led to retention of many mummies within the trellis each year.

Disease control trials. Different spray-timing regimes were constructed by varying the number and timing of applications of the DMI fungicide myclobutanil (112 g/ha) at 2-week intervals throughout the growing season. The timing regimes consisted of combinations of the following fungicide applications, listed with respect to host phenology: spray $1,10-\mathrm{cm}$ shoot growth; spray 2 , 25 -cm shoot growth; spray 3 , immediate pre-bloom; and sprays 4 , 5 , and 6 at 2, 4, and 6 weeks, respectively, after the immediate prebloom spray. Different arrays of spray timing regimes were used in different years and at the different locations.

Individual treatment plots consisted of the three adjacent vines between a pair of trellis posts and were arranged in a randomized

TABLE 1. Effect of fungicide timing on black rot incidence on clusters of Vitis interspecific hybrid 'Aurore' at Dresden, NY from 1995 to $1999^{u}$

\begin{tabular}{lccccc}
\hline & \multicolumn{5}{c}{ Symptomatic clusters $(\%)^{\mathrm{v}}$} \\
\cline { 2 - 6 } Spray timing $^{\mathrm{w}}$ & $1995^{\mathrm{xy}}$ & $1996^{\mathrm{x}}$ & $1997^{\mathrm{yz}}$ & $1998^{\mathrm{yz}}$ & $1999^{\mathrm{x}}$ \\
\hline Unsprayed check & $99 \mathrm{a}$ & $60 \mathrm{a}$ & $45 \mathrm{a}$ & $82 \mathrm{a}$ & $85 \mathrm{a}$ \\
$1,2,3,4,5,6$ & n.i. & $60 \mathrm{a}$ & n.i. & n.i. & n.i. \\
$1,2,3,4,5$ & $5 \mathrm{~d}$ & $1 \mathrm{~cd}$ & $1 \mathrm{~b}$ & $0 \mathrm{c}$ & $1 \mathrm{~d}$ \\
$1,2,3,4$ & $44 \mathrm{bc}$ & $4 \mathrm{~cd}$ & $0 \mathrm{~b}$ & $1 \mathrm{c}$ & n.i. \\
$2,3,4,5$ & $0 \mathrm{e}$ & $0 \mathrm{~d}$ & $0 \mathrm{~b}$ & $0 \mathrm{c}$ & $0 \mathrm{~d}$ \\
$3,4,5,6$ & n.i. & n.i. & $0 \mathrm{c}$ & $0 \mathrm{c}$ & n.i. \\
$3,4,5$ & $3 \mathrm{de}$ & $0 \mathrm{~d}$ & $0 \mathrm{c}$ & $0 \mathrm{c}$ & $0 \mathrm{~d}$ \\
$2,3,4$ & $25 \mathrm{c}$ & n.i. & n.i. & n.i. & $2 \mathrm{~d}$ \\
3,4 & n.i. & $5 \mathrm{c}$ & $2 \mathrm{bc}$ & $3 \mathrm{c}$ & $2 \mathrm{~d}$ \\
$4,5,6$ & n.i. & n.i. & n.i. & $0 \mathrm{c}$ & n.i. \\
4,5 & $42 \mathrm{c}$ & $4 \mathrm{~cd}$ & $2 \mathrm{bc}$ & $2 \mathrm{c}$ & $3 \mathrm{~d}$ \\
$1,2,3$ & $86 \mathrm{ab}$ & $27 \mathrm{~b}$ & $4 \mathrm{~b}$ & $17 \mathrm{~b}$ & $14 \mathrm{c}$ \\
1,2 & n.i. & n.i. & n.i. & n.i. & $41 \mathrm{~b}$ \\
\hline
\end{tabular}

u Parts of this table were published previously in a symposium article (14); n.i. = treatment not included in the year indicated.

${ }^{v}$ Values represent the means of four replicate plots per treatment. Means within a column followed by a common letter are not significantly different $(P \geq 0.05)$ as determined by the Waller-Duncan $k$-ratio $t$ test.

${ }^{w}$ Myclobutanil (112 g/ha) was applied to indicated treatments at the following approximate phenological stages: $1=10-\mathrm{cm}$ shoot growth; $2=25-\mathrm{cm}$ shoot growth; $3=$ immediate prebloom; and 4,5 , and $6=2,4$, and 6 weeks, respectively, after immediate prebloom.

x Infection periods were recorded at a nearby vineyard in Himrod, NY, on 2, 11, 26, and 30 June; and 11, 14, and 16 July, at which time the weather station became dysfunctional. Subsequent rain events were recorded at Geneva, NY, on 17, 19, 24, 25, 26, 28, and 29 July; and 4, 5, 6, 12, and 13 August.

y To reduce the heterogeneity of the variance as indicated in residual plots, the least significant digit was added to all mean values which then were logtransformed prior to analysis of variance and mean separation.

${ }^{\mathrm{z}}$ Infection periods with respect to spray dates are reported in Table 2. complete block design with four replications. A split-plot design was incorporated into the Naples experiment to determine the effect of sanitation (subplots) on inoculum availability, disease development, and control. In December, when all Dresden plots were cane-pruned by hand and mummies were dropped to the ground as per standard viticultural practice, mummies in half of the Naples plots similarly were removed from the trellis and dropped to the ground beneath the vines; for comparison, those in the remaining vines were left undisturbed, and most remained following subsequent mechanical hedging. Each trial location was surrounded by at least two border rows to minimize the drift of fungicide from outside the trial, and all fungicide applications (468 liters/ha prebloom and 936 liters/ha postbloom) were made using a hooded-boom sprayer, which minimized potential drift among plots.

Disease assessments on foliage and fruit were made at least weekly at both locations throughout the 1998 and 1999 seasons to quantify disease progress and the potential availability of secondary inoculum. For each assessment, the number of leaves containing at least one lesion-bearing pycnidium per shoot was recorded for 10 randomly selected shoots per plot, as was the proportion of infected berries on each of 50 clusters, using the Horsfall-Barratt rating scale (16). These ratings were converted to percentage values using Elanco conversion tables (Elanco Products Co., Indianapolis, IN). Fifty clusters were harvested at the end of each season from the center two-thirds of every treatment plot, and the incidence of cluster infection was determined. A berry was considered infected if any portion of it exhibited black rot symptoms. For clusters from the Naples plots, berries also were examined individually to determine the percentage of symptomatic berries per cluster (disease severity). If heterogeneity in the variance was indicated in residual plots of disease incidence and severity values, the least significant digit was added to these values, which then were log-transformed to help stabilize the variance. Data were subjected to analysis of variance (ANOVA), and treatment means were separated using the Waller-Duncan $k$ ratio $t$ test $(P \leq 0.05)$. For the split-plot experiment at Naples, the sanitation-treatment variable also was tested in the ANOVA, and the treatment means were separated with the Waller-Duncan $k$ ratio $t$ test within each split variable only. The means of common treatments within each split-plot were compared using paired $t$ tests. All statistical analyses were performed using SAS (SAS Institute, Cary, NC).

Inoculum dynamics. At both sites, individual rain events were declared putative black rot infection periods if the requisite hours of leaf wetness at the prevailing average temperature, as determined by Spotts (33), were achieved. From 1997 to 1999 at Dresden and in 1998 and 1999 at Naples, hourly temperature, leaf wetness, and rainfall were monitored with Campbell CR-10X dataloggers (Campbell Scientific, Logan, UT). Two uncoated leaf wetness sensors, one inside and one outside the canopy, were placed at a $45^{\circ}$ angle, $1.5 \mathrm{~m}$ above the ground. The grapevine leaves were considered wet when both leaf wetness sensors registered 0.8 (i.e., at least $48 \mathrm{~min}$ of each hour registered as wet) or above. In 1995, infection periods were inferred from weather and leaf wetness data collected in a vineyard at Himrod, NY, approximately $12 \mathrm{~km}$ from Dresden, and in 1996, infection periods were inferred from similar data collected at the New York State Agricultural Experiment Station, Geneva, approximately $9 \mathrm{~km}$ from Dresden.

From 1996 to 1999, the release of ascosporic primary inoculum during rain events was quantified using a Burkard volumetric spore trap (Burkard Mfg. Co., Rickmansworth, Hertfordshire, England) placed in a central location within each trial site. Spore traps were installed each year (one at each site) prior to bud-break and adjusted to sample 10 liter of air/min. The airflow of each trap was calibrated when the tapes were changed. Tapes were collected from the field every 5 to 7 days, cut into $48-\mathrm{mm}$ seg- 
ments corresponding to a 24-h period, and mounted on glass slides with $0.05 \%$ cotton blue in lactoglycerol. Transects perpendicular to the direction of movement of the tape were examined for ascospores at $\times 300$ magnification using phase contrast microscopy. Ascospores were distinguished on the basis of their size and distinctive "footprint" shape $(7,28)$. Ascospores were counted in one transect every $2 \mathrm{~mm}$ apart, beginning with the hour corresponding to the beginning of a rainfall event and continuing until two consecutive transects without ascospores were observed. These values were summed and reported as (i) the total number sampled throughout a season, facilitating comparisons of inoculum pressure among seasons and vineyards; and (ii) the percentage of the season's total recovered after each rain event, facilitating comparisons of ascospore release dynamics.

At the Naples vineyard, availability of both ascospores and conidia was compared from mummies retained in the trellis versus those dropped to the ground. For the 1998 and 1999 seasons, mummies were obtained from vines in December of the previous year and placed in mesh bags measuring approximately 30 by $30 \mathrm{~cm}$. One bag was suspended in the trellis and one was laid on the bare ground beneath the vines. No effort was made to trim back the grape shoots that subsequently grew around the bag in the trellis or to trim weeds growing around the one on the ground. These mummies were collected weekly during the growing season, and collection immediately after a rainfall was avoided when possible. Twenty-five mummies from each bag were soaked for approximately $3 \mathrm{~h}$ in $15 \mathrm{ml}$ of sterile distilled water and the number of conidia and ascospores recovered was counted in four aliquots per sample, using a hemacytometer. Data were expressed as the number of conidia and ascospores recovered per mummy at each collection and time. In April 2000, mummies from the Naples vines were moved, for convenience of subsequent sampling, to a nearby research vineyard located at the NY State Agricultural Experiment Station in Geneva. Pairs of mesh bags were placed, one in the trellis and one on the ground, near the four corners of the grape block. Replicate 25-mummy samples were collected weekly from each of the eight locations and assayed as described previously. The cumulative percentages of ascospores and conidia detected through each sampling date were linearized using a probit transformation. These data were regressed against time, and the mean slopes corresponding to mummies collected from the ground versus the trellis were compared with a two-sample $t$ test.

\section{RESULTS}

Dresden experiment. Spray timing significantly affected the incidence of infected clusters $(P \leq 0.0001)$ during all 5 years the trial was run in Dresden. In 1995, myclobutanil applied immediately prior to bloom plus 2 and 4 weeks later (sprays 3, 4,

TABLE 2. Relationship between phenologically based spray timing, infection period occurrence, and ascospore trapping of Guignardia bidwellii in an 'Aurore' vineyard in Dresden, NY from 1996 to 1999

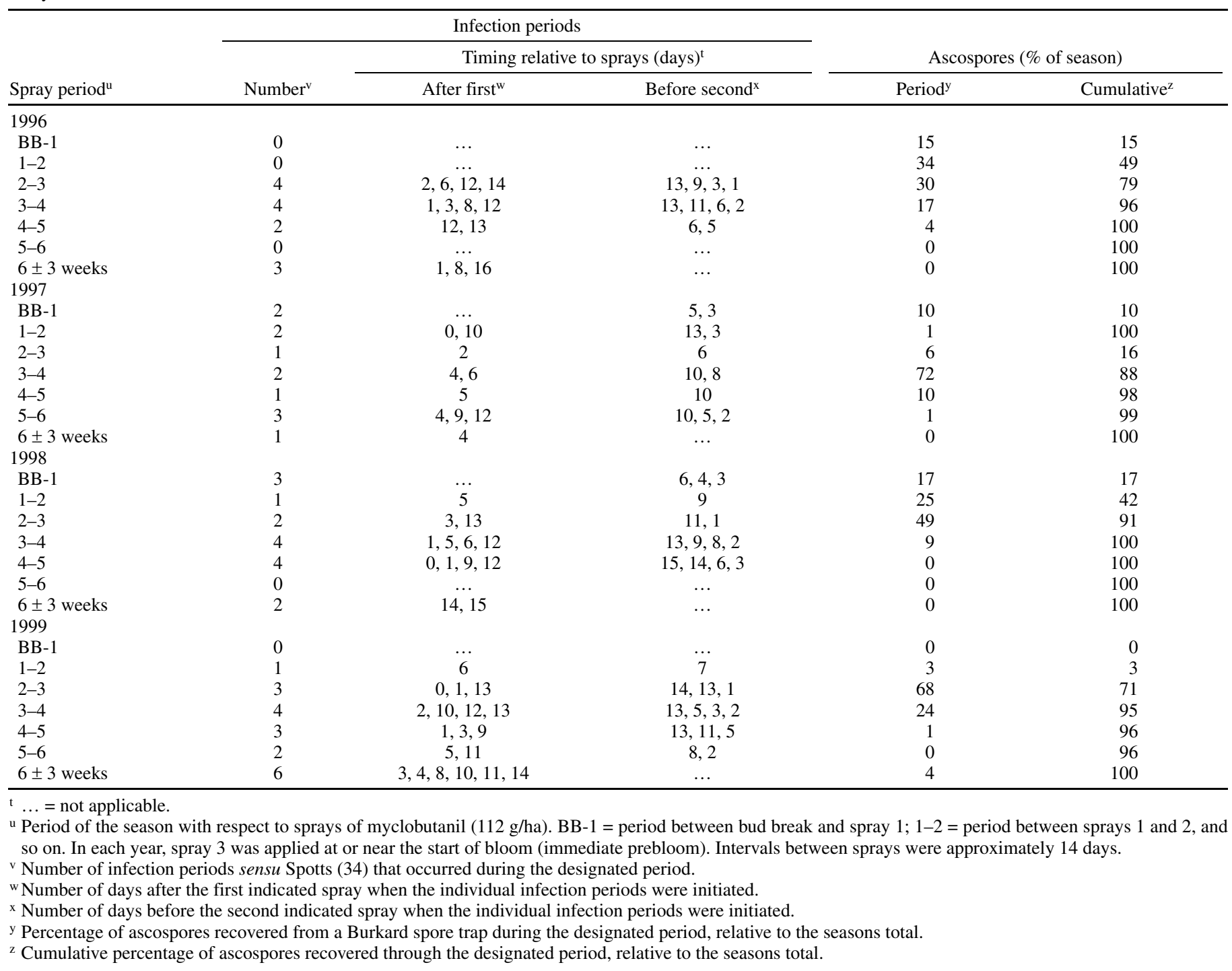


and 5, respectively) provided $97 \%$ control relative to the unsprayed check. Additional sprays 2 and 4 weeks before the immediate prebloom application (i.e., sprays 2 and 1, respectively) provided no further control, although infection periods occurred after each of them (Table 1). However, when any of the sprays from immediately before bloom through 4 weeks later were omitted, control was seriously compromised, and no significant $(P \leq 0.05)$ control was provided when both postbloom sprays were omitted (Table 1).

Complete control of fruit rot was obtained in 1996 when myclobutanil was applied immediately prior to bloom plus 2 and 4 weeks later (Table 1). Therefore, additional sprays 2 and 4 weeks before the immediate prebloom treatment provided no further benefit, even though $30 \%$ of the season's ascospores were trapped during four infection periods in the 13 days prior to the immediate prebloom application. Four additional infection periods occurred between the immediate prebloom and subsequent spray (Table 2), which appeared to be the most important application of the season. For instance, providing just the three prebloom sprays resulted in only $55 \%$ control of disease incidence at harvest, despite the near dissipation of ascosporic inoculum by 2 weeks after the third application (Table 2). However, continuing this program to include the first postbloom application, or merely providing the first two postbloom sprays, resulted in nearly complete control (Table 1).

In 1997, disease pressure (as measured by disease incidence in the unsprayed check treatment) was lower than in any of the other 4 years, and all fungicide timing programs provided complete to near-complete control (Table 1). Ascospores were trapped from
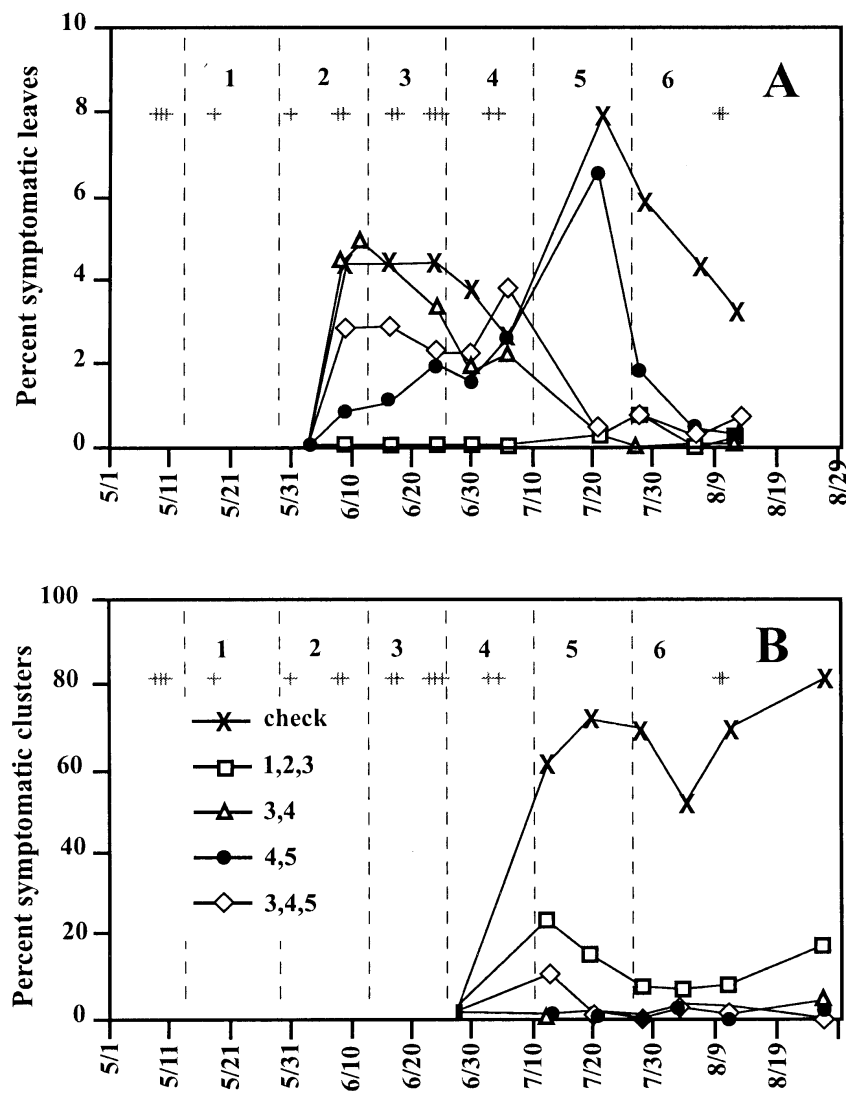

Assessment date

Fig. 1. Progress of black rot on A, leaves and $\mathbf{B}$, fruit of Vitis interspecific hybrid 'Aurore' subjected to different fungicide timing regimes at Dresden in 1998. Dashed vertical lines and numerals to their right indicate the timing of specific myclobutanil applications as designated in Tables 1 and 2 (e.g., spray 3 = immediate prebloom application). The "+" signs indicate the occurrence of individual infection periods sensu Spotts (34). the time the shoots were approximately $25 \mathrm{~cm}$ long until almost 6 weeks after bloom, although 88 and $98 \%$ were trapped prior to the immediate prebloom spray and within 2 weeks thereafter, respectively (Table 2).

In 1998, 12 rain events occurred prior to the immediate prebloom spray, leading to the discharge of $91 \%$ of seasonal ascosporic inoculum and the development of six forecasted infection periods (Table 2). However, applying all three prebloom sprays provided only $79 \%$ control of cluster disease incidence at harvest (Table 1). In contrast, merely applying the first postbloom spray plus that immediately before or after it provided complete control (Table 1). Six additional rain events, during which the remaining seasonal supply of ascospores was discharged, occurred between the immediate prebloom and first postbloom sprays, although ascospore discharge (2\% of the seasonal total) was detected only during a single infection period (23 June) after the calyx caps had fallen to expose young berries to infection (14) (Table 2). During this period, pycnidia-bearing leaf lesions were not present on vines that received all three prebloom applications, although they were present in every other treatment (Fig. 1). When only the three prebloom sprays were applied, diseased clusters were not detected until the assessment 21 days after the 23 June infection period, at which time its incidence was substantial (Fig. 1). No infection periods occurred between the second and third postbloom sprays (Table 2), precluding the possibility for additional disease spread before berries developed age-related resistance (15).
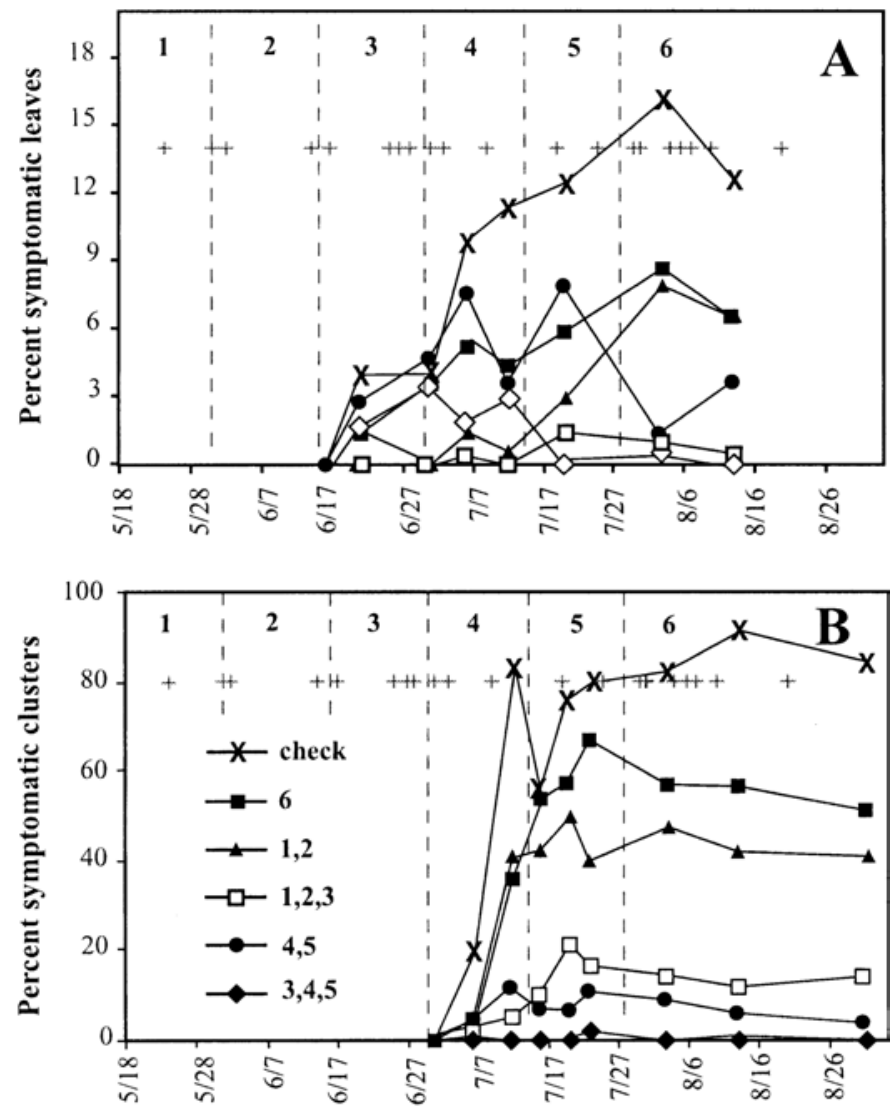

Assessment Date

Fig. 2. Progress of black rot on $\mathbf{A}$, leaves and $\mathbf{B}$, fruit of Vitis interspecific hybrid 'Aurore' subjected to different fungicide timing regimes at Dresden in 1999. Dashed vertical lines and numerals to their right indicate the timing of specific fungicide applications as designated in Tables 1 and 2 (e.g., spray $3=$ immediate prebloom application); note that spray 1 was applied on 18 May. Individual treatments are identified by the various sprays that were applied. The "+" signs indicate the occurrence of individual infection periods sensu Spotts (34). 
In 1999, complete control of fruit rot was obtained once again when myclobutanil was applied immediately prior to bloom plus 2 and 4 weeks later, and near-complete control was provided when only the first postbloom spray plus that immediately before or after it were applied (Table 1). When assessed on 6 July, cluster infection incidence was negligible in treatments receiving either the first two or first three sprays. However, when assessed 6 days later, disease incidence had increased to $40 \%$ when the third spray was omitted, but remained at only $5 \%$ when it was applied (Fig. 2). Considering an incubation period of approximately 13 to 21 days on young berries (15), these data suggest that substantial disease was initiated during the three infection periods from 25 to 28 June (i.e., 10 to 13 days after the immediate prebloom spray and 2 to 5 days before the first postbloom application) (Table 2). Leaf lesions were not detectable in any treatment until the assessment of 20 June, 5 days after the immediate prebloom spray (Fig. 2). Vines receiving all three prebloom sprays or the immediate prebloom and first two postbloom sprays remained virtually free of foliar disease throughout the assessment period. No leaf lesions were apparent on vines that received only the first two prebloom sprays until the assessment on 6 July ( $>4$ weeks after the second application), but disease incidence increased sharply during the ensuing month (Fig. 2).

Naples experiment. Both the quantity and, in some cases, the apparent dispersal dynamics of $G$. bidwellii inoculum differed markedly at the Naples site relative to the vineyard in Dresden. In 1998 , the total number of ascospores counted in the transects of the spore trap tape from Naples was over 20 -fold greater than that sampled from the Dresden site and was nearly five times greater in 1999. Overwintered mummies collected from the ground (where all mummies also overwintered in Dresden) released fewer total spores over a shorter period of time than did those collected from within the trellis (Fig. 3). In 1998, mummies collected from the ground or within the trellis released equivalent numbers of both ascospores and conidia through bloom (late June), but very few spores were recovered throughout the re-
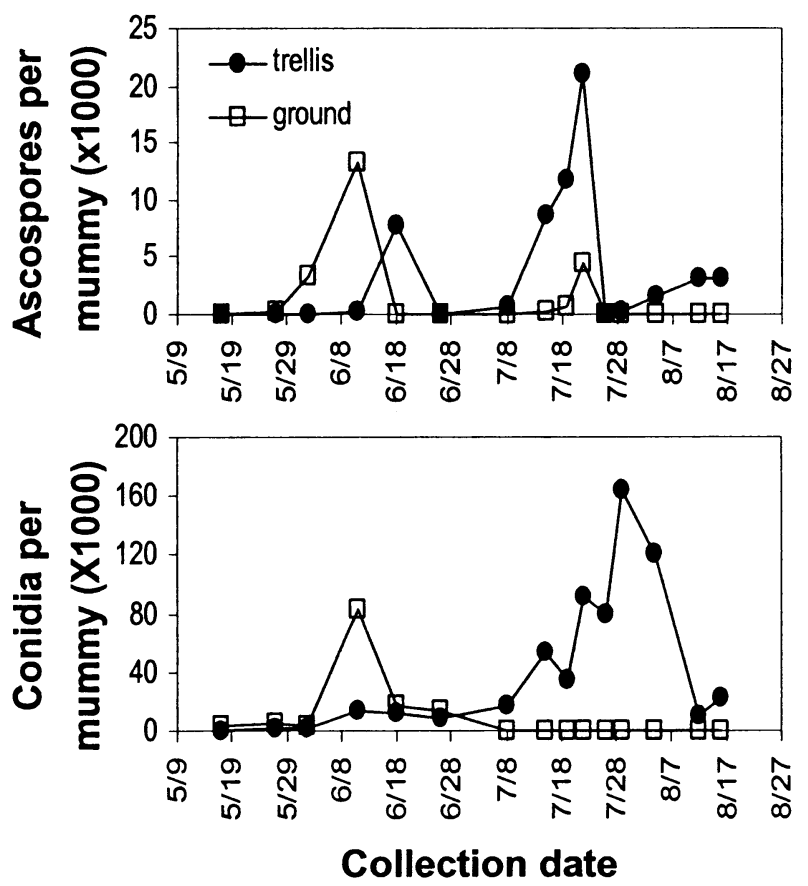

Fig. 3. Detection, in 1998, of ascospores and conidia of Guignardia bidwellii from overwintered mummies retained either in the trellis or dropped to the ground beneath the vines at Naples in December of the previous year. Mummies were collected on the indicated dates, soaked in sterile distilled water, and the number of spores recovered was determined with the aid of a hemacytometer. mainder of the season from those on the ground. In contrast, approximately 4 to $8 \times 10^{4}$ ascospores per mummy were recovered from each collection in the trellis through the end of July, and approximately 10 times this many conidia were recovered from each collection through mid-August (Fig. 3). This same pattern was evident both in the following year (data not shown) and when replicated samples were assessed in 2000 (i.e., inoculum from overwintering mummies was virtually depleted by bloom). Maximal recovery from the trellis-collected mummies occurred in mid- to late July (4 to 6 weeks after the start of bloom), and the numbers of conidia from the latter exceeded those of ascospores by an order of magnitude at most sampling dates (Fig. 4). When the cumulative percentages of spores from these samples were linearized using a probit transformation and regressed against time, two sample $t$ tests confirmed that the positive slopes of the regression lines were significantly greater for both conidia and ascospores released from mummies on the ground versus those in the trellis $(P \leq 0.003$ and 0.03 , respectively).

In the 1998 field trial, both spray timing and mummy location (sanitation) significantly affected disease severity at harvest $(P \leq$ 0.0001 and 0.01 , respectively). Applying just the immediate prebloom plus two postbloom sprays, a program that provided virtually complete control in each of the 5 years at Dresden, provided only 76 to $77 \%$ control in the two sanitation subtreatments at Naples (Table 3). In further contrast to the Dresden site, incorporating an additional spray into this basic program (i.e., 2 weeks prior to the immediate prebloom application) improved the control of berry infection modestly but significantly $(P \leq 0.05)$ in both subtreatments (i.e., to 85 and $88 \%$ relative to the check when mummies were retained in the trellis or dropped to the ground, respectively) (Table 3). In the unsprayed check plots where mummies had been removed from the trellis, the frequency of berry disease increased from 30 to $87 \%$ between the 15 and 24 July
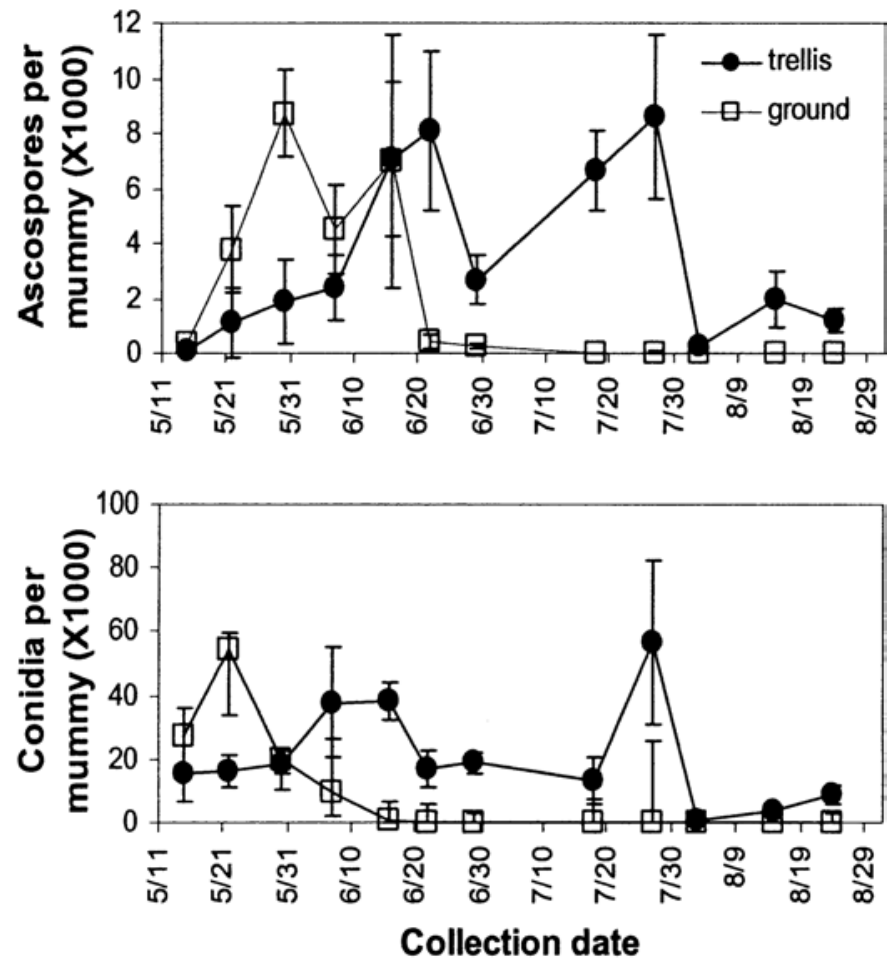

Fig. 4. Detection, in 2000, of ascospores and conidia of Guignardia bidwellii from mummies collected from Naples, NY, and overwintered in a vineyard in Geneva, NY, either in the trellis or on the ground beneath the vines (mummies were dropped to the ground in December and moved to Geneva in April). Each data point represents the mean from four replicate samples; bars indicate the standard error. First bloom on 'Delaware' vines was approximately 15 June. 
assessment dates. These data suggest that multiple infections were initiated during one or more of the three infection periods that occurred between 30 June and 8 July (Fig. 5D) (i.e., 4 to 12 days after spray 4 and 13 to 5 days before spray 5) (Table 4). Indeed, berry infections in plots receiving these two applications increased only modestly between the 15 and 24 July assessment dates (Fig. 5D). In addition to ascosporic infections, this rapid progression of disease in unsprayed plots may have resulted from conidia originating from previously rotted berries, which had reached an incidence of $21 \%$ by the assessment on 7 July (Fig. 5D), or from infected leaves, which had reached an incidence of $17 \%$ by the same date (Fig. 5B). Approximately $95 \%$ of the trapped ascosporic inoculum was recovered through the first day after spray 3 (Table 4), but three prebloom sprays provided only $32 \%$ control of berry rot when mummies were dropped to the ground (Table 3). In these subplots, application of the three sprays delayed symptom appearance on both leaves and fruit until the assessment on 15 July (Fig. 5D); thus, conidia from these sources had no potential to initiate secondary disease until the next infection period on 10 August, by which time fruit should have become resistant (15). However, $4 \%$ of the season's trapped ascosporic inoculum was recovered during the three apparently critical infection periods of 30 June to $8 \mathrm{July}$, which occurred 18 to 26 days after the application of spray 3 (Table 4; Fig. 5D).

Disease progress was even more rapid and pronounced on berries in subplots where mummies were retained in the trellis (Fig. 5C): nearly all unsprayed fruit became diseased and application of just three prebloom sprays provided only $9 \%$ control relative to the check. Whereas removing mummies from the trellis significantly reduced berry rot in unsprayed plots and those receiving only prebloom applications $(P<0.01$ and 0.004 , respectively), sanitation had no significant effect on final disease levels in any of the three spray regimes that included postbloom applications (Table 3).

As in the previous year, both spray-timing treatment and mummy location significantly affected fruit rot levels in 1999

TABLE 3. Effect of fungicide timing and sanitation on the incidence of black rot on berries of Vitis $\times$ labruscana 'Delaware' at Naples, NY in 1998 and 1999

\begin{tabular}{|c|c|c|c|c|c|c|}
\hline \multirow[b]{3}{*}{ Spray timing ${ }^{\mathrm{w}}$} & \multicolumn{6}{|c|}{ Symptomatic berries $(\%)^{\mathrm{v}}$} \\
\hline & \multicolumn{3}{|c|}{1998} & \multicolumn{3}{|c|}{1999} \\
\hline & Ground $^{\mathrm{x}}$ & Trellis $^{y}$ & $P$ value ${ }^{\mathrm{z}}$ & Ground $^{x}$ & Trellis ${ }^{y}$ & $P$ value ${ }^{\mathrm{z}}$ \\
\hline $1,2,3,4,5$ & n.i. & n.i. & n.i. & $8 \mathrm{~cd}$ & $18 \mathrm{~b}$ & 0.1 \\
\hline $2,3,4,5$ & $9 \mathrm{~d}$ & $14 \mathrm{~d}$ & 0.2 & $5 \mathrm{~d}$ & $18 \mathrm{~b}$ & 0.05 \\
\hline $3,4,5,6$ & $17 \mathrm{c}$ & $27 \mathrm{c}$ & 0.1 & n.i. & n.i. & n.i. \\
\hline $3,4,5$ & $18 \mathrm{c}$ & $21 \mathrm{c}$ & 0.5 & $11 \mathrm{c}$ & $12 \mathrm{~b}$ & 0.8 \\
\hline
\end{tabular}

${ }^{v}$ Means within a column followed by a common letter are not significantly different $(P \geq 0.05)$ as determined by the Waller-Duncan $k$-ratio $t$ test; $n$.i. $=$ treatment was not included in that year.

${ }^{\mathrm{w}}$ Myclobutanil (112 g/ha) was applied to indicated treatments at the following approximate phenological stages: $1=10$ - $\mathrm{cm}$ shoot growth; $2=25-\mathrm{cm}$ shoot growth; 3 = immediate prebloom; and 4, 5, and $6=2,4$, and 6 weeks, respectively, after the immediate prebloom application.

$x$ Mummies in the trellis were dropped to the ground near the time of dormant pruning.

${ }^{y}$ Mummies that persisted after mechanical pruning were retained in the trellis.

${ }^{\mathrm{z}} P$ values determined in paired $t$ tests comparing means between the ground and trellis treatments.
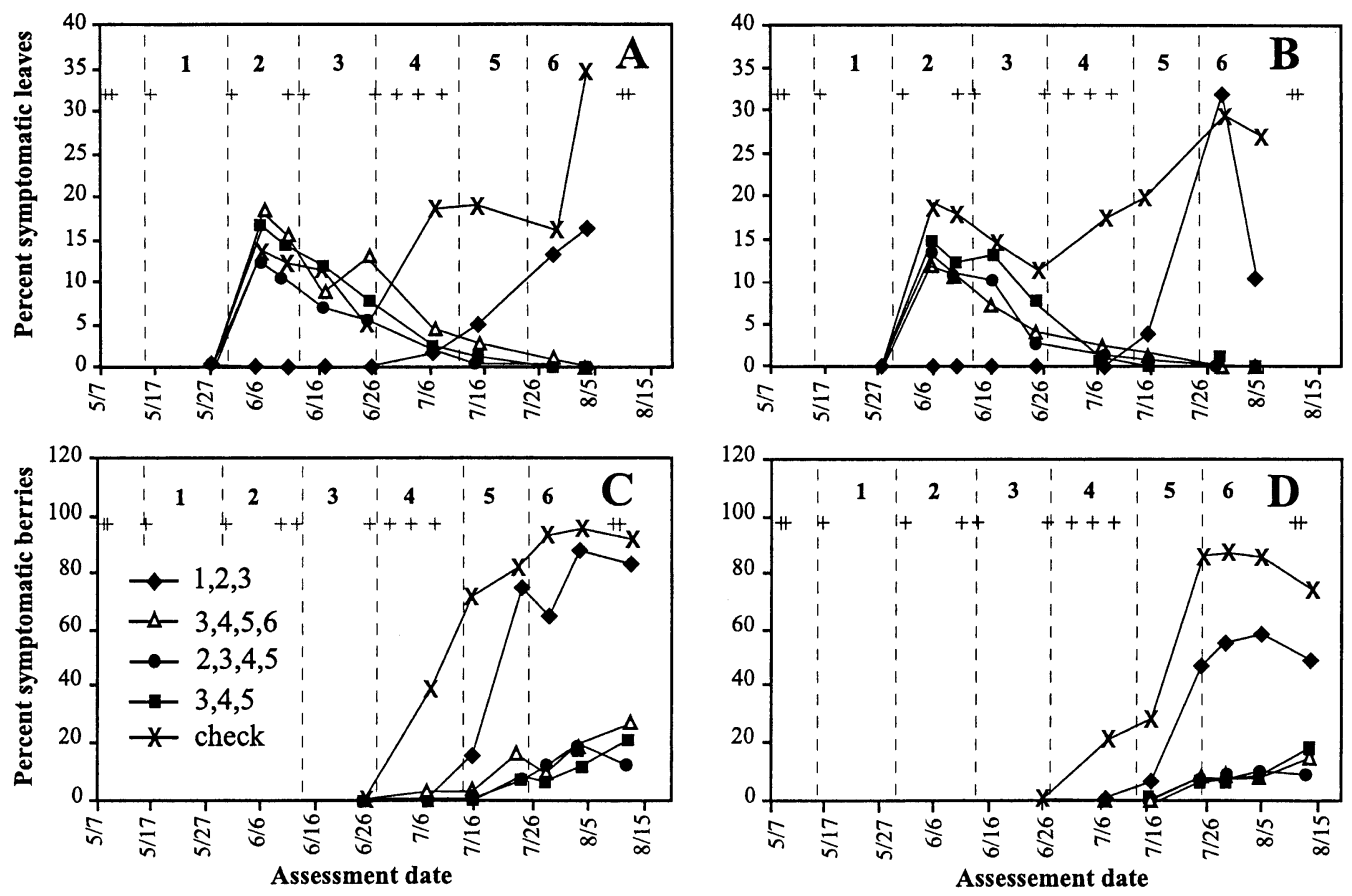

Fig. 5. Progress of black rot on $\mathbf{A}$ and $\mathbf{B}$, leaves and $\mathbf{C}$ and $\mathbf{D}$, fruit of Vitis $\times$ labruscana 'Delaware' subjected to different fungicide timing regimes at Naples in 1998. Mummies were A and C, retained in the trellis or $\mathbf{B}$ and $\mathbf{D}$, dropped to the ground beneath the vines prior to the growing season. Dashed vertical lines and numerals to their right indicate the timing of specific fungicide applications as designated in Tables 3 and 4 (e.g., spray $3=$ immediate prebloom application); individual treatments are identified by the various sprays that were applied. The "+" signs indicate the occurrence of individual infection periods sensu Spotts (34). 
( $P \leq 0.0001$ and 0.0002 , respectively), and the immediate prebloom plus two postbloom sprays provided only 76 to $81 \%$ control of berry infection (Table 3). Applying one or two additional prebloom sprays improved control modestly when mummies were removed to the ground but not at all when they were retained in the trellis (Table 3), even though five infection periods, associated with $44 \%$ of the trapped ascosporic inoculum, occurred prior to the immediate prebloom application (Table 4). Considering a 13- to 21-day incubation period (15), the earliest berry infections, first apparent during the assessments on 8 and 12 July (Fig. 6C and D), likely were initiated during the infection periods that occurred between the immediate prebloom and first postbloom sprays, when $19 \%$ of the trapped ascosporic inoculum was recovered (Table 4). Very little secondary inoculum should have been available from leaf lesions at that time, because foliar disease was virtually undetectable until later (Fig. 6A and B).

When mummies were retained in the trellis, applying just the first two prebloom sprays provided no control of berry infection at any of the disease assessment dates, although adding a third (immediate) prebloom spray reduced the frequency of diseased berries by approximately $80 \%$ (relative to the unsprayed check) during the early assessments. However, the control provided by this treatment declined over time as disease progressed in the absence of additional fungicidal protection, until there was no significant effect at harvest (Fig. 6C). In contrast, when mummies were dropped to the ground, applying just these two or three prebloom sprays provided 30 and $49 \%$ control of berry infection at harvest, respectively (Table 3). Dropping mummies also improved control of berry infection when two or three prebloom sprays were combined with the postbloom applications (i.e., 91 and $86 \%$ control, respectively, versus just $64 \%$ when mummies were retained in the trellis) $(P<0.05$ and 0.1 , respectively) (Table 3$)$.

\section{DISCUSSION}

Although traditional recommendations for fungicidal control of black rot indicate that applications could be necessary for the entirety of a 3-month period between early shoot growth and veraison (28), we found that the critical period for such treatments was considerably narrower. At the Dresden site, where pruning and sanitation practices were similar to those used in most local vineyards and where overwintering inoculum levels appeared to be moderately higher in comparison (personal observations), applications of myclobutanil immediately prior to bloom plus 2 and 4 weeks later provided virtually complete control of fruit rot while reducing the standard number of seasonal fungicide applications by $50 \%$ or more. Application of the first postbloom spray (spray 4), relatively soon after anthesis, appeared to be particularly influential. Fertilized ovaries remain highly susceptible as they develop into young fruit (15). Indeed, the first postbloom spray in combination with just one more, either 2 weeks before or after it, provided control that was statistically equivalent to the three-spray program in 4 out of the 5 years tested, although control was significantly compromised when either the immediate prebloom or second postbloom spray was omitted in the remaining season.

Despite substantial ascospore discharge prior to the immediate prebloom period, very few leaf lesions were observed near bloom, and earlier protection of the foliage to prevent the development of secondary inoculum in these lesions provided no additional benefit if the immediate prebloom and first two postbloom sprays were applied. Furthermore, we found that additional sprays applied $>4$ weeks postbloom provided no benefit so long as these three sprays had been applied previously. Jermini and Gessler (19) similarly reported little correlation between black rot incidence on leaves and fruit in an unsprayed vineyard of $V$. vinifera 'Merlot' in southern Switzerland, and found that no new fruit infections occurred later than mid-July (6 weeks after full bloom) despite inoculum availability and weather conditions conducive to disease development. In our companion study (15), field inoculations showed that fruit of Vitis $\times$ labruscana 'Concord' were highly susceptible to black rot for 2 to 4 weeks after the start of bloom and lost all detectable susceptibility when challenged $>4$ to 5 weeks postbloom; fruit of $V$. vinifera 'Chardonnay' and 'Riesling' also lost most of their susceptibility by this time, although they maintained some susceptibility for 6 to 7 weeks after the start of bloom, depending on the season. Thus, we conclude that myclobutanil applied only at the start of bloom plus 2 and 4 weeks later provided excellent control in each year of the

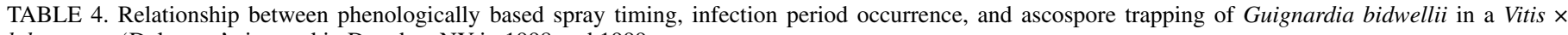
labruscana 'Delaware' vineyard in Dresden, NY in 1998 and 1999

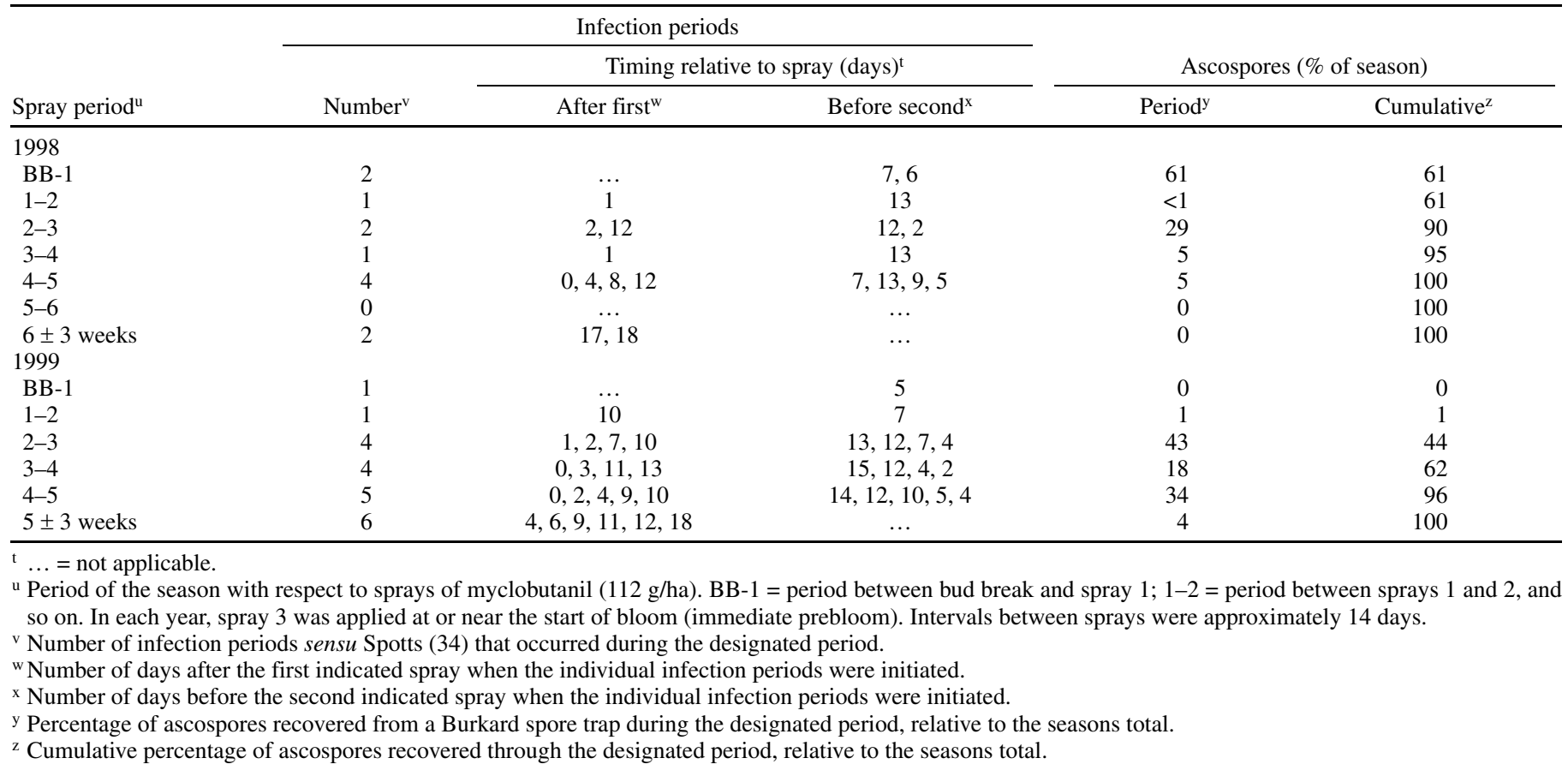


Dresden trial because (i) fruit were protected throughout most or all of their period of susceptibility, (ii) omission of earlier sprays resulted in negligible levels of foliar infection and any secondary inoculum from these was controlled by later applications to the fruit, and (iii) infection periods subsequent to dissipation of fungicide from the final application were inconsequential even on fruit yet to acquire full age-related resistance, due to a lack of available inoculum. The latter assumption is predicated on the facts that primary inoculum had been exhausted by this time and that the three sprays had controlled most potential sources of secondary inoculum. Furthermore, it is likely that the intensity of sporulation from the few early leaf lesions that developed before sprays were initiated had been reduced greatly following previous wetting events (24).

High inoculum pressure at Naples, and perhaps restricted spray penetration through the extremely dense canopies, apparently limited the efficacy of even the best spray regimes at this site. Nevertheless, the critical importance of myclobutanil applications from the immediate prebloom stage through 4 weeks later was clearly evident here as well, and analysis of disease progress indicated that virtually all fruit infections occurred during this period. However, in contrast to the results from Dresden, an additional application 2 weeks before the immediate prebloom spray generally provided an additional measure of control. This was especially apparent in 1998, when foliar infections were abundant prior to bloom.

When mummies were collected from the trellis, ascospores and conidia were recovered throughout July and into August, often in large quantities, whereas very few spores were recovered after late June when mummies were collected from the ground; these results are similar to those noted by Becker and Pearson $(1,2)$. Additionally, up to 10 times as many spores were recovered over the course of the season from mummies retained in the trellis relative to those dropped to the ground. Thus, when mummies were retained in the canopy, not only were absolute inoculum levels greater than when they were removed to the ground, but the temporal dynamics of inoculum release also shifted to provide far more risk of infection after bloom, when fruit were present and highly susceptible to the pathogen. Exacerbating these effects even further, splash dispersal of conidia to the developing berries should have been far more likely from mummies within the trellis relative to those on the ground, since this process is greatly facilitated by gravity and also occurs primarily over distances of $<20 \mathrm{~cm}$ (22). Fungicide applications during the postbloom period tended to diminish these effects in some, but not all, individual treatments (Table 3 ). In addition to the detrimental effects of mummy retention, mechanical hedge pruning at the Naples site also resulted in extremely dense canopies that appeared to restrict the penetration of fungicide sprays into the fruit zone. For instance, assuming an incubation period of up to 3 weeks on young fruit and up to 5 weeks shortly before they become resistant (15), disease progress curves clearly reveal that berry infections were occurring during the early postbloom period even in plots that were being sprayed at that time (Figs. 5C and D and 6C and D). Among a sample of 50 monoconidal isolates of G. bidwellii collected from the Naples vineyard, the range of sensitivities to myclobutanil was similar to that in a nearby baseline population (13), indicating that fungicide resistance was not a likely contributor to the incomplete control provided by postbloom sprays. Therefore, we believe that incomplete spray coverage within the
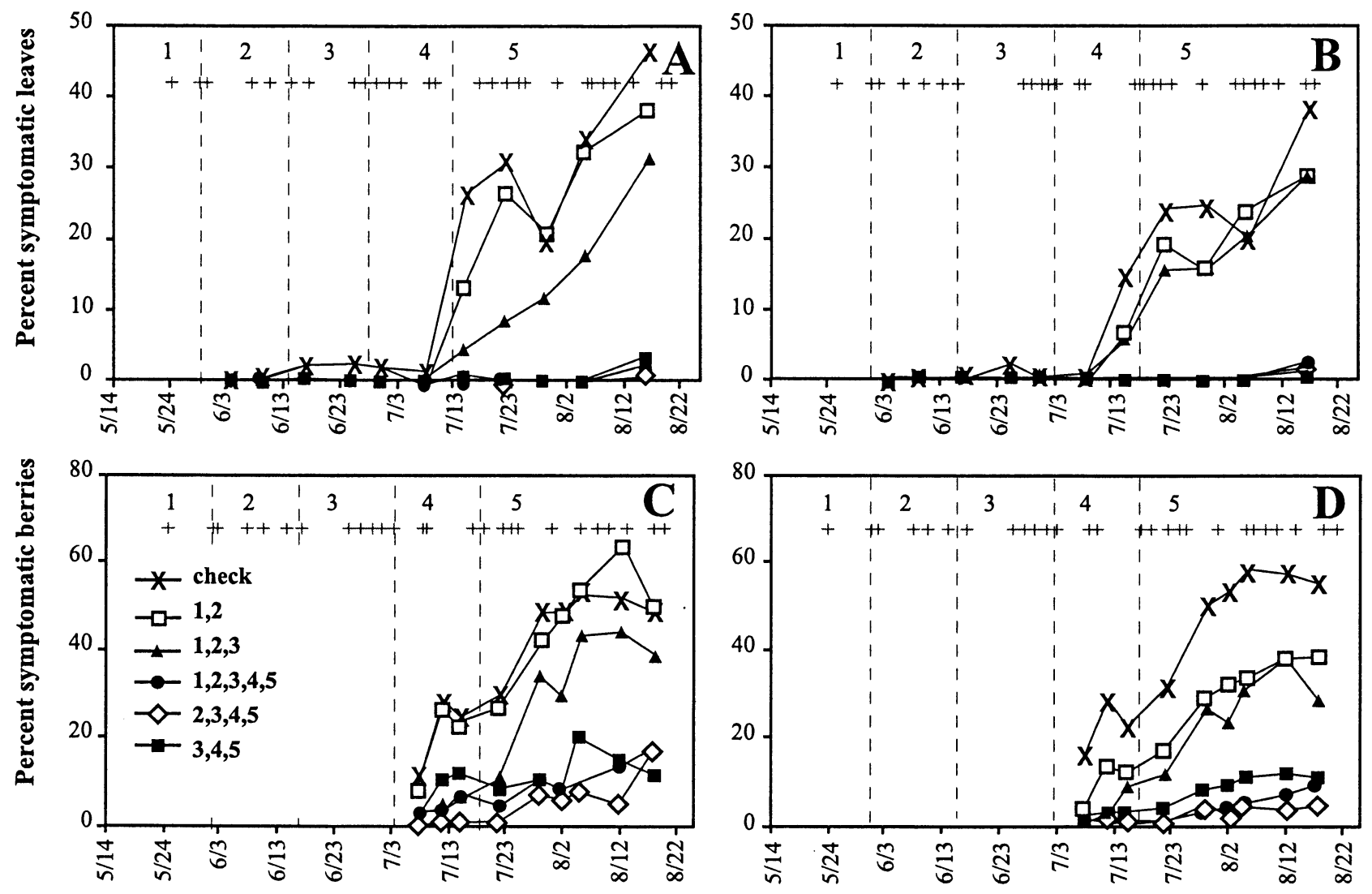

Assessment date

Assessment date

Fig. 6. Progress of black rot on $\mathbf{A}$ and $\mathbf{B}$, leaves and $\mathbf{C}$ and D, fruit of Vitis $\times$ labruscana 'Delaware' subjected to different fungicide timing regimes at Naples in 1999. Mummies were $\mathbf{A}$ and $\mathbf{C}$, retained in the trellis or $\mathbf{B}$ and $\mathbf{D}$, dropped to the ground beneath the vines prior to the growing season. Dashed vertical lines and numerals to their right indicate the timing of specific fungicide applications as designated in Tables 3 and 4 (e.g., spray $3=$ immediate prebloom application); note that spray 1 was applied on 14 May. Individual treatments are identified by the various sprays that were applied. The "+" signs indicate the occurrence of individual infection periods sensu Spotts (34). Panels $\mathbf{C}$ and $\mathbf{D}$ were published previously as part of a symposium article (14). 
extremely dense postbloom canopy contributed to these results, although it was not measured directly.

When we applied only prebloom sprays at either site, control was consistently, and often severely, compromised, irrespective of the near completion of ascospore discharge shortly after the final application. Notably, when postbloom sprays were omitted from such programs, the first leaf and cluster infections typically were not evident until assessments 3 to 4 weeks after the immediate prebloom application, consistent with the approximate incubation period following the final postbloom ascospore discharge. Thus, even without subsequent secondary spread, a small percentage of the seasonal ascospore supply seemingly can cause substantial damage in the absence of fungicidal protection, as apparently occurred at both vineyards in 1998. Losses due to these final ascosporic infections could be further exacerbated if weather conditions favor secondary spread throughout the remaining period of fruit susceptibility, as occurred in 1999. Such findings illustrate the critical importance of protecting valuable host tissues while they are highly susceptible to infection unless inoculum is known to be truly limiting. They are consistent with the considerable improvement in black rot control obtained when Gadoury et al. (10) extended sprays until fruit set (approximately the time of our first postbloom spray), rather than terminating the sprays at bloom at the putative depletion of the ascospore supply.

In this study, we have demonstrated the utility of focusing a limited number of fungicide applications on the period of maximum host susceptibility, a principle that also has been demonstrated for control of powdery mildew (Uncinula necator) fruit infections on an assortment of grapevine species and cultivars $(11,12,35)$. However, our contrasting results at Dresden versus Naples also demonstrate the pronounced influence of primary inoculum levels on both the qualitative and quantitative success of various fungicide programs. Sanitation is a concept widely recommended for integrated disease management programs, but its benefits are rarely quantified in specific pathosystems. In this study, we substantially improved control of black rot simply by pruning mummies out of the vine during dormancy, although we did not attempt to examine additional sanitation practices, such as cultivation to bury them. Nevertheless, sanitation can clearly be an important component of an integrated black rot management program, and may be critical if highly effective fungicides are not employed (e.g., organic production systems). Finally, it should be recognized that our results were obtained with serial applications of myclobutanil and may have differed had we similarly applied protectant fungicides such as mancozeb, or newer products with little curative activity, (e.g., the QoI fungicides) $(13,36)$. In contrast with such materials, initial applications of myclobutanil at the immediate prebloom stage may have masked the potential importance of earlier foliar infections by providing significant curative activity against them. For instance, myclobutanil prevented foliar lesion development when applied to grape seedlings within 6 days after inoculation; prevented subsequent pycnidium formation when applied approximately 10 days after inoculation; and reduced the production of conidia within pycnidia by 65 to $80 \%$ when applied within 3 to 4 days after the first appearance of symptoms (13). In contrast, the QoI fungicide azoxystrobin provides far less curative activity against black rot (13) but provides significantly more residual (protective) activity on berries than does myclobutanil (W. F. Wilcox, unpublished data). These differences illustrate the need to understand the specifics of fungicidal activities in addition to epidemiological factors when trying to devise efficient disease management strategies.

\section{LITERATURE CITED}

1. Becker, C. M., and Pearson, R. C. 1992. Patterns of spore release from black rot (Guignardia bidwellii) infected grape mummies that overwintered on the ground or in the canopy. (Abstr.) Phytopathology 82:1084.
2. Becker, C. M., and Pearson, R. C. 1993. Evaluation of cultural control strategies for managing black rot (Guignardia bidwellii) of grapes. (Abstr.) Phytopathology 83:1377.

3. Becker, C. M., and Pearson, R. C. 1996. Black rot lesions on overwintered canes of Euvitis supply conidia of Guignardia bidwellii for primary inoculum in the spring. Plant Dis. 80:24-27.

4. Ellis, M. A., Madden, L. V., and Wilson, L. L. 1986. Electronic grape black rot predictor for scheduling fungicides with curative activity. Plant Dis. 70:938-940.

5. Emele, L. R., Wilcox, W. F., Gadoury, D. M., and Seem, R. C. 1998. Critical period for control of black rot of grape. (Abstr.) Phytopathology 88:25.

6. Emele, L. R., Wilcox, W. F., Gadoury, D. M., and Seem, R. C. 1999. Retaining overwintered mummies within the trellis increases grape black rot severity. (Abstr.) Phytopathology 89:23.

7. Ferrin, D. M., and Ramsdell, D. C. 1977. Ascospore dispersal and infection of grapes by Guignardia bidwellii, the causal agent of grape black rot disease. Phytopathology 67:1501-1505.

8. Ferrin, D. M., and Ramsdell, D. C. 1978. Influence of conidia dispersal and environment on infection of grape by Guignardia bidwellii. Phytopathology 68:892-895.

9. Gadoury, D. M. 1993. Integrating management decisions for several pests in fruit production. Plant Dis. 77:299-302.

10. Gadoury, D. M., Pearson, R. C., Seem, R. C., and Park, E. W. 1997. Integrating the control programs for fungal diseases of grapevine in the Northeastern United States. Vitic. Enol. Sci. 52:140-147.

11. Gadoury, D. M., Seem, R. C., Ficke, A., and Wilcox, W. F. 2001. The epidemiology of powdery mildew on Concord grapes. Phytopathology 91:948-955.

12. Gadoury, D. M., Seem, R. C., Ficke, A., and Wilcox, W. F. 2003. Ontogenic resistance to powdery mildew in grape berries. Phytopathology 93:547-555.

13. Hoffman, L. E., and Wilcox, W. F. 2003. Factors influencing the efficacy of myclobutanil and azoxystrobin for control of grape black rot. Plant Dis. 87:273-281.

14. Hoffman, L. E., and Wilcox, W. F. 2002. Utilizing epidemiological investigations to optimize the management of grape black rot. Phytopathology 92:676-680.

15. Hoffman, L. E., Wilcox, W. F., Gadoury, D. M., and Seem, R. C. 2002. Influence of grape berry age on susceptibility to Guignardia bidwellii and its incubation period length. Phytopathology 92:1068-1076.

16. Horsfall, J. G., and Barratt, R. W. 1945. An improved grading system for measuring plant diseases. (Abstr.) Phytopathology 36:655.

17. Janex-Favre, M. C., Parguey-Leduc, A., and Jailloux, F. 1993. The ontogeny of pycnidia of Guignardia bidwellii in culture. Mycol. Res. 97: 1333-1339.

18. Janex-Favre, M. C., Parguey-Leduc, A., and Jailloux, F. 1996. The ontogeny of perithecia of Guignardia bidwellii. Mycol. Res. 100:875880 .

19. Jermini, M., and Gessler, C. 1996. Epidemiology and control of grape black rot in southern Switzerland. Plant Dis. 80:322-325.

20. Kuo, K., and Hoch, H. C. 1996. The parasitic relationship between Phyllosticta ampelicida and Vitis vinifera. Mycologia 88:626-634.

21. Kuo, K., and Hoch, H. C. 1996. Germination of Phyllosticta ampelicida pycnidiospores: Prerequisite of adhesion to the substratum and the relationship of substratum wettability. Fungal Genet. Biol. 20:18-29.

22. Madden, L. V. 1992. Rainfall and the dispersal of fungal spores. Adv. Plant Pathol. 8:39-79.

23. Manns, T. F. 1928. Grape disease control in Delaware. Univ. Del. Agric. Exp. Stn. Bull. 154.

24. Northover, P. R. 1998. The relationship of the number of wetting periods and accumulated degree-days to sporulation of Guignardia bidwellii (Ellis) Viala and Ravaz in vineyards. M.Sc. thesis. Penn. State University.

25. Price, B. S. 1892. Black rot of the grape: Life history. Treatment. Texas Agric. Exp. Stn. Bull. 32:217-231.

26. Price, J. C. C., and Neal, D. C. 1926. Two important grape diseases. Miss. Agric. Exp. Stn. Circ. 68.

27. Pscheidt, J., and Pearson, R. C. 1989. Effect of grapevine training systems and pruning practices on occurrence of Phomopsis cane and leaf spot. Plant Dis. 73:825-828.

28. Ramsdell, D. C., and Milholland, R. D. 1988. Black rot. Pages 15-17 in: Compendium of Grape Diseases. R. C. Pearson and A. C. Goheen, eds. The American Phytopathological Society, St. Paul, MN.

29. Reddick, D. 1911. The black rot disease of grapes. Cornell Univ. Agric. Exp. Stn. Bull. 293:289-364.

30. Scribner, F. L. 1886. Botanical characters of the black rot, Physalospora Bidwellii Sacc. Bot. Gaz. 11:297-303.

31. Scribner, F. L., and Viala, P. 1888. Black rot (Laestadia bidwellii). Dep. Agric. Bot. Div. Bull. 7.

32. Shaw, B. D., Kuo, K., and Hoch, H. C. 1998. Germination and appres- 
sorium development of Phyllosticta ampelicida pycnidiospores. Mycologia 90:258-268.

33. Spotts, R. A. 1977. Effect of leaf wetness duration and temperature on the infectivity of Guignardia bidwellii on grape leaves. Phytopathology 76: 1378-1381.

34. Spotts, R. A. 1980. Infection of grape by Guignardia bidwellii-factors affecting lesion development, conidia dispersal and conidial populations on leaves. Phytopathology 70:252-255.

35. Wilcox, W. F., and Riegel, D. G. 1997. Evaluation of fungicide programs for control of grapevine powdery mildew, 1997. Fungic. Nematicide Tests 53:107-108.

36. Wong, F. P., and Wilcox, W. F. 2001. Comparative physical modes of action of azoxystrobin, mancozeb, and metalaxyl against Plasmopara viticola (grapevine downy mildew). Plant Dis. 85:649-656. 